\title{
RUANG BUDAYA PADA PROSES DAUR HIDUP (KELAHIRAN) DI DUSUN WEDORO GRESIK
}

\author{
Mike Yuanita $^{1}$, Antariksa ${ }^{2}$, Lisa Dwi Wulandari ${ }^{3}$ \\ ${ }^{1}$ Mahasiswa Program Magister Arsitektur Lingkungan Binaan /Fakultas Teknik, Universitas Brawijaya Malang \\ 2 Dosen Program Magister Arsitektur Lingkungan Binaan /Fakultas Teknik, Universitas Brawijaya Malang \\ ${ }^{3}$ Dosen Program Magister Arsitektur Lingkungan Binaan /Fakultas Teknik, Universitas Brawijaya Malang \\ Email :miEke_yuan@yahoo.co.id
}

\begin{abstract}
ABSTRAK
Salah satu Dusun di Gresik yang masih memegang ritual budaya adalah Dusun Wedoro. Kegiatan daur hidup (kelahiran) secara bertahap dilaksanakan, dari proses sebelum melahirkan hingga pasca melahirkan. Setiap kegiatan ritual memiliki ruang yang membentuk sebuah ruang budaya. Metode yang digunakan adalah Deskriptif Kualitatif. Analisa menggunakan supperimpose peta atas ruang ruang yang terbentuk, dari masingmasing kegiatan ritual. Ruang budaya yang terbentuk tidak hanya karena ruang, waktu pelaksanaan juga berpengaruh terhadap terbentuknya ruang budaya. Pada proses kelahiran ruang budaya di hasilkan secara mikro di hunian.
\end{abstract}

Kata kunci: Ruang budaya, kelahiran, Wedoro

\section{ABSTRACT}

One village in Gresik which still holds cultural ritual is Hamlet Wedoro . Activity life cycle (birth) gradually implemented, from the prenatal to postpartum . Every ritual activity has a space that forms a cultural space. The method used is qualitative descriptive. Analysis using supperimpose map above room space formed, of each ritual activities. Cultural space which is formed not only because of space, the execution time also affects the formation of cultural space. At the birth of the cultural space generated by the micro in residential

Keywords: Cultural space, Birth, Wedoro

\section{Pendahuluan}

Budaya masyarakat sangat mempengaruhi pembentukan tata ruang permukiman. Hubungan tersebut membentuk suatu korelasi yang kuat. Selain budaya, perkembangan masyarakat juga mempengaruhi elemen permukiman. Permukiman Dusun Wedoro memiliki beberapa keunikan, Dusun ini masuk ke dalam lingkungan yang alami dimana banyak terdapat tumbuhan hijau sehinggga sirkulasi udara berjalan baik dan seimbang, masyarakatnya pun masih tradisional, material bangunan yang digunakan menggunakan material bambu, jarak antar rumah tidak dibatasi pagar yang menjulang tinggi, mereka cukup menggunakan tanaman sebagai pembatas antar rumah yang satu dengan yang lain.

Pada proses daur hidup, contohnya Upacara kehamilan diantaranya ada selamatan 4bulan dan 7 bulan, upacara kelahiran, diantara ada selamatan Brokohan, Pupak puser, selapan dino, 3 wulanan, 7 wulan, setahun, mlaku, Pernikahan, dan Selamatan kematian. Ritual pembentuk ruang budaya diperlukan untuk dikaji karena setiap kegiatan ritual cenderung memiliki pola yang berbeda-beda, terutama pada bentukan ruangnya, sehingga 
pengaplikasian ritual dalam kegiatan yang menggunakan ruang budaya membentuk suatu pola lintasan dalam permukiman.

Perilaku dapat juga dijabarkan sebagai proses interaksi antara kepribadian dan lingkungan. Lingkungan mengandung stimulus, kemudian akan ditanggapi oleh manusia dalam bentuk respon, respon inilah yang disebut perilaku. Oleh karena itu, manusia dengan keterbatasan daya tahan sistem psikofisiknya menciptakan suatu lingkungan buatan sebagai perantara dirinya dengan lingkungan alamiah (natural world) dan lingkungan masyarakat beradab (civilized society). Lingkungan buatan bersifat nyata dan diciptakan atas dasar pengalaman empiris manusia dengan lingkungannya. Hubungan manusia dengan lingkungan binaannya merupakan suatu jalinan saling ketergantungan satu dengan yang lainnya. Artinya manusia dan lingkungan saling mempengaruhi karena lingkungan bukan hanya sebagai wadah manusia beraktivitas, melainkan juga menjadi bagian integral dari pola perilaku manusia [Laurens, 2004]. Rapoport [1969] dalam kajian arsitektur lingkungan dan perilaku mengungkapkan pengaruh ruang terhadap perilaku manusia, yaitu fungsi atau pemakaian dari ruang tersebut yang dirancang untuk memenuhi fungsi yang fleksibel, dapat saja timbul dari aktifitas suatu masyarakat dengan tujuan dan fungsi tertentu yang sifatnya sementara, setelah aktifitas telah selesai maka ruangan yang terbentuk hilang.

\section{Bahan dan Metode}

Studi ini menggunakan metode kualitatif-deskriptif, dengan tujuan mencari informasi secara faktual dengan melihat fenomena yang terjadi di lapangan, dan melakukan wawancara kemudian fenomena tersebut di analisis dengan membandingkan foto data visual. Pada saat pengumpulan data juga dilakukan penggambaran peta perilaku (behavioral mapping) untuk menunjukkan tempat aktifitas berlangsung dan pergerakan pelaku dalam palaksanaan aktifitas tersebut. Behavioral mapping digambarkan dalam sketsa atau diagram mengenai suatu area tempat manusia melakukan berbagai kegiatannya. Tujuannya adalah untuk menggambarkan perilaku dalam peta, mengidentifikasikan jenis dan frekuensi perilaku serta menunjukkan kaitan antara perilaku tersebut dengan wujud perancangan yang spesifik.

\section{Hasil dan Pembahasan}

Setelah adanya pernikahan, sudah sewajarnya bila satu keluarga dikaruniai sebuah anak, dalam proses kelahiran terdapat beberapa tradisi ritual yang dilangsungkan sebelum proses kelahiran terjadi. Di dusun Wedoro terdapat hubungan yang baik antara bidan desa dan Dukun bayi, bila terjadi proses kelahiran yang berlangsung di Dusun Wedoro dua pihak antara Bidan dan Dukun bayi diharuskan hadir dan melakukan kerjasama, hal ini sesuai dengan kesepakatan diantara warga dusun. Sebelum proses melahirkan, pihak perempuan yang akan melahirkan dapat menghubungi Bidan Desa terlebih dahulu untuk memastikan proses kelahiran, sedangkan Dukun Bayi akan di panggil ketika proses melahirkan akan berjalan. Dukun bayi tidak hanya membantu dalam proses kelahiran, namun pada setiap kegiatan yang dilangsungkan saat bayi tersebut sudah lahir.

\subsection{Waktu, aktivitas, dan pelaku tradisi kelahiran}

Dalam proses kelahiran dapat dibagi menjadi dua bagian penting, yang pertama alah proses saat bayi masih di dalam kandungan dan proses setelah bayi di luar kandungan.

a. Sebelum melahirkan 
Dalam kebiasaan di Dusun Wedoro terdapat kegiatan-kegiaan dilaksanakan ketika proses mengandung, diantaranya selamatan 3 bulanan dan selamatan 7 bulanan atau yang biasa disebut dengan istilah tingkepan.

b. Setelah melahirkan

Tradisi kelahiran yang terjadi dusun Wedoro dimulai dengan adanya brokohan, yaitu selamatan atas kelahiran bayi, yang dilangsungkan sesaat setelah bayi kembali ke rumah. Setelah brokohan tradisi lanjutan adalah Aqiqah yang biasanya dilaksanakan 7 hari setelah bayi lahir dan hal ini dilakukan bagi kalangan yang mampu, untuk keluarga yang kurang mampu acara aqiqahan dapat diundur sesuai dengan kemampuan keluarga, Acara selanjutnya, yakni Pupak Puser yang biasanya dilaksanakan 2 (dua) hingga 3 (tiga) minggu setelah kelahiran, masing-masng bayi memiliki kemampuan untuk pupak puser yang berbeda-beda.Selamatan 3 bulanan atas kelahiran bayi dan selamatan 7 bulanan juga dilaksanakan, dan bila bayi adalah laki-laki diakhiri dengan adanya khitan. Khitan dapat dilaksanakan setalah anak lakilaki berusia kurang lebih 10 bulan.

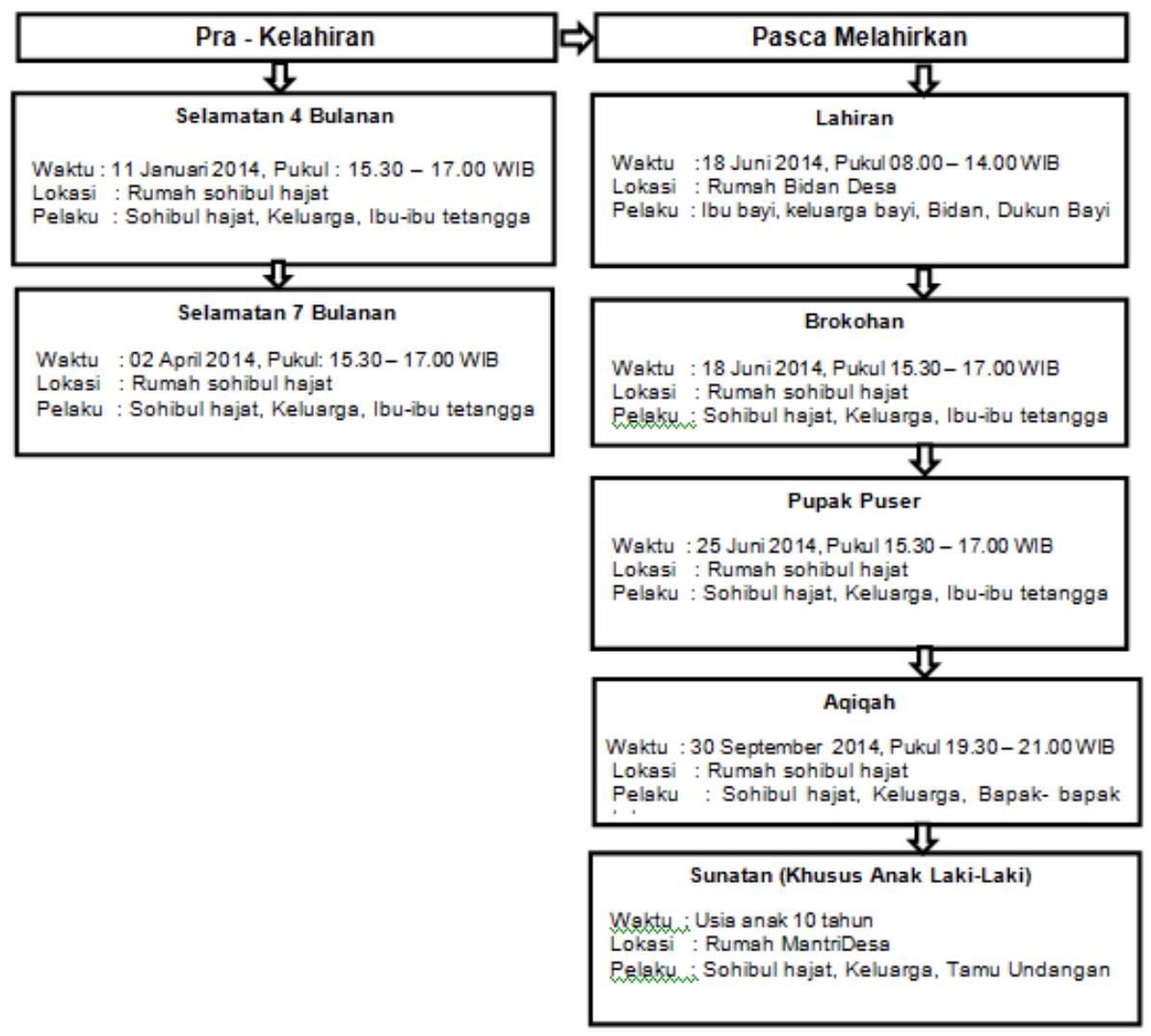

Gambar 1. Alur tahapan kelahiran

\subsection{Pembentukan ruang tradisi kelahiran}

Tahapan yang terjadi saat proses kelahiran, antara lain, yaitu:

A. Kegiatan Pra Kelahiran

a. Selamatan 4 bulanan

Kegiatan ini dilaksanakan ketika ibu telah mengetahui bahwa dirinya telah hamil, dan usia kandungan telah berusia 3 bulan lebih mendekati 4 bulan. 
Selamatan 4 bulanan merupakan ritual kelahiran awal. Berapa hal yang menjadi landasan peringatan 4 bulan kehamilan, antara lain, yaitu Sebagai tanda syukur seorang hamba kepada tuhannya, Allah SWT yang telah memberikan anugerah dengan memberikan amanah berupa seorang buah hati, anak dan sebagai pendidikan prenatal (pendidikan sebelum lahir) bagi janin yang mulai hidup atau mulai diberi ruh, yang kelak bertujuan agar sang buah hati menjadi anak yang shaleh/shalehah, faham agama, serta menjadi anak yang mencintai dan mengamalkan alquran.

Di Dusun Wedoro kegiatan selamatan 4 bulanan dapat dilakukan melalui 2 cara, cara yang pertama dengan mengundang beberapa orang tetangga dan cara yang kedua melakukan selamatan di masjid atau musholla terdekat yang ada di rumah. Cara yang dilakukan bila melakukan selamatan di rumah antara lain, yaitu, kepala keluarga mengundang tetangga sekitar yang biasa disebut dengan istilah uwar-uwar, yang di undang adalah kelompok bapak-bapak, dan saat selamatan 4 bulanan bacaan yang selalu dibaca adalah Surat Yusuf, pelaksanaan selamatan 4 bulanan mengunakan ruang tamu untuk pelaksanaaan selamatan, karena undangan tidak terlalu banyak, hanya tetangga sekitar saja. Bila selamatan 4 bulanan dilakukan di musholla atau masjid terdekat maka, kepala keluarga menghubungi ta'mir masjid atau pengelola musholla memberitahukan bahwa akan mengadakan selamatan 4 bulanan yang dilaksanakan setelah sholat maghrib, tak'mir masjid atau kyai akan menginformasikan kepada jamaa'ahnya bahwa akan diadakan selamatan 4 bulanan. Pemilik acara akan membawa makanan dalam jumlah besar yang ditempatkan di tempeh, berupa nasi dan lauk sebanyak 44 takir.

b. Selamatan 7 bulanan

Hal yang sama dilakukan ketika mengadakan kegiatan selamatan 7 bulanan, Mitoni atau selamatan tujuh bulanan, dilakukan setelah kehamilan seorang ibu genap usia 7 bulan atau lebih. Tujuan mitoni atau tingkeban (selamatan 7 bulanan) agar ibu dan janin selalu dijaga dalam kesejahteraan dan keselamatan.

Di Dusun Wedoro, kegiatan tingkepan ini dilakukan di rumah yang bersangkutan, dengan mengundang tetangga dusun, menyebarkan undangan, biasanya sampai 2 RT yang diundang. Kegiatan tingkeban ini dilaksanakan pada jam 19.00 - 21.00 WIB, dan sebelumnya telah diadakan beberapa acara,yaitu:

1. Hataman qur'an dengan mengundang hafid dari luar dusun yang berlangsung dari pagi hari jam 05.00 sampai dengan 14.00, hataman qur'an dilakukan di ruang tamu pemilik acara.

2. Bowoh, yaitu setelah proses hataman qur'an selesai beberapa tetangga ada yang melakukan bowoh dengan membawa beras, gula atau beras kepada pemilik acara yang dilakukan biasanya tetangga datang sebelum acara tingkeban dimulai sekitar pukul 16.30 sampai dengan 18.00, penerimaan kedatangan tamu tetangga dilakukan di ruang tamu, dan menaruh hasil bowoh diletakkan diruang keluarga. Tetangga yang telah datang untuk bowoh tadi ketika pulang mendapatkan makanan, rujak dan kue procot yang dimasukkan ke dalam masing-masing tas yang dibawa. 

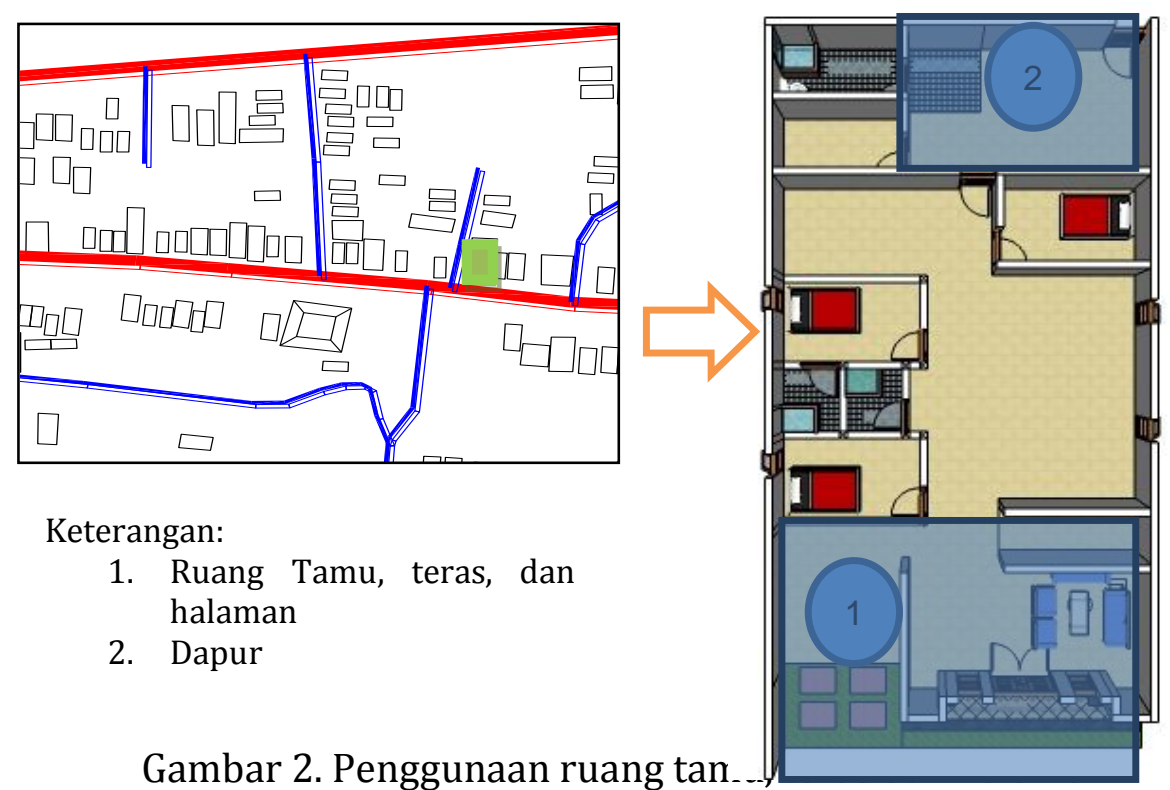

Gambar 2. Penggunaan ruang tan. untuk selamatan 7 bulanan

3. Acara inti tingkeban, yaitu pengajian atau tahlil yang dilakukan oleh bapak-bapak, kurang lebih 200 orang yang diundang untuk mengikuti acara ini, sehingga ruang yang digunakan cukup luas, yaitu meliputi ruang tamu, teras, garasi dan halaman. Acara tingkeban ini berlangsung antara pukul 19.00 hingga 21.00. Pengunaan ruang hampir sama seperti penggunaan ruang di acara selamatan 7 bulanan.

Setelah acara tingkeban selesai digelar, ibu yang sedang mengandung 7 bulan melakukan mandi dengan bunga setaman (7 rupa), kemudian melakukan tradisi pecah telur membelah cengkir kelapa yang dilakukan oleh suami.

Urutan acara tingkeban ini bermacam-macam, tergantung kondisi ekonomi dari masing-masing keluarga, dan kegiatan lain adalah penyiapan konsumsi yang dilakukan oleh beberapa ibu-ibu dari tetangga sekitar dan saudara.Dalam tradisi Jawa, yang membuat bumbu rujak dilakukan oleh ibu yang membantu dirumah. Jika bumbunya rasanya asin, biasanya jabang bayi lahir perempuan. Bila tidak asin (kebanyakan garam), biasanya lahir laki-laki.Akan tetapi karna teknologi medis sudah sedemikian canggih, sampai ditemukan USG empat dimensi, jenis kelamin bayi sudah dapat diketahui lebih dini. 


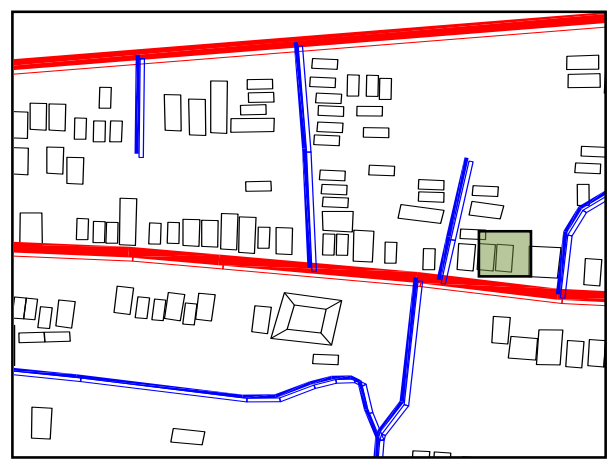

Keterangan:

1. Ruang Tamu

2. Ruang Keluarga

3. Dapur

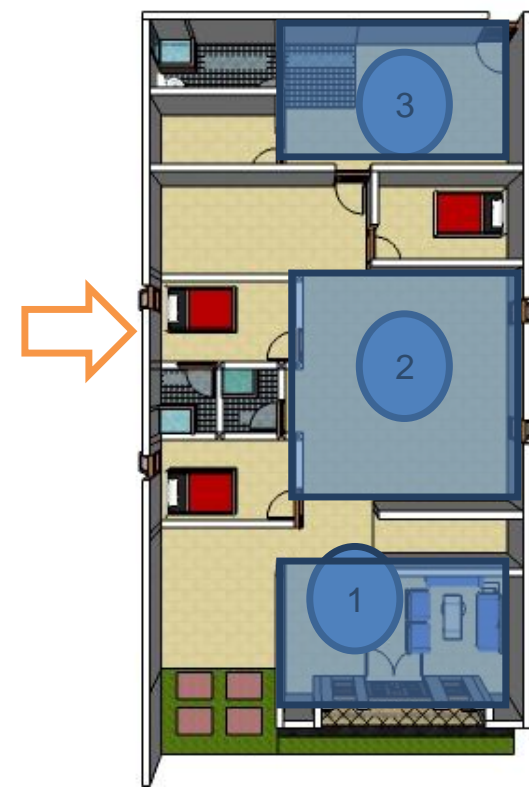

Gambar 3. Penggunaan ruang tamu, dan ruang keluarga pada kegiatan bowoh

\section{B. Kegiatan Kelahiran}

a. Lahiran

Setelah melalui tahapan selamatan 4 bulan dan 7 bulanan (tingkeban), dan menunggu selama 9 bulan 10 hari, proses kelahiran tiba, proses lahiran bisa di lakukan dirumah bidan desa, di rumah sakit ataupun diklinik, namun khusus di Dusun Wedoro proses kelahiran dilakukan di rumah bidan desa, ketika proses kelahiran bidan desa tidak bekerja sendiri, bidan desa didampingi oleh Dukun bayi. Setelah proses kelahiran telah selesai, bila tidak ada masalah dengan ibu maupun bayi, biasanya langsung diijinkan untuk kembali ke rumah. Dalam proses melahirkan, bidan juga membersihkan ari-ari bayi yang diserahkan kepada pihak keluarga untuk di kuburkan.

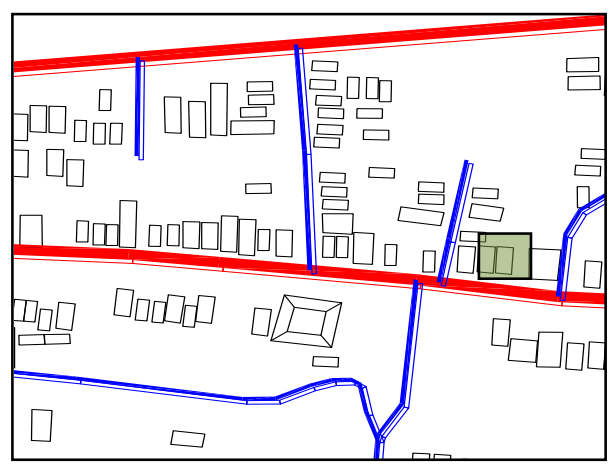

Keterangan:

1. Halaman Depan

2. Halaman Belakang

3. Dapur

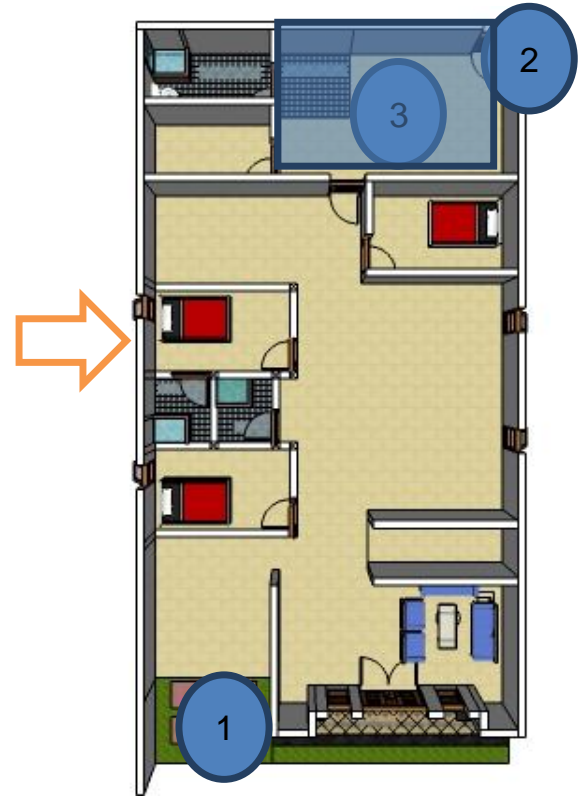

Gambar 4. Peletakan ari-ari pada daerah sekitaran rumah 
b. Brokohan

Kegiatan ini berlangsung ketika bayi dan ibu sudah kemballi ke rumah, acara ini dimaksudkan dalam rangka penyambutan bayi, acara brokohan ini diikuti oleh ibu-ibu tetangga, dan dipimpin oleh Dukun Bayi. Kegiatan yang berlangsung saat brokohan antara lain, membacakan doa untuk kesehatan dan keselamatan bayi. Selain kegiatan brokohan keluarga meyiapkan makanan untuk dibawa pulang oleh tetangga yang hadir pada saat brokohan, dan menyiapkan semacam sesajen untuk diberikan kepada Dukun Bayi. Ruang yang digunakan untuk brokohan menggunakan ruang tamu dan teras, dan menggunakan ruang tengah untuk menyiapkan makanan dan dapur untuk mempersiapkan konsumsi (Gambar 5).
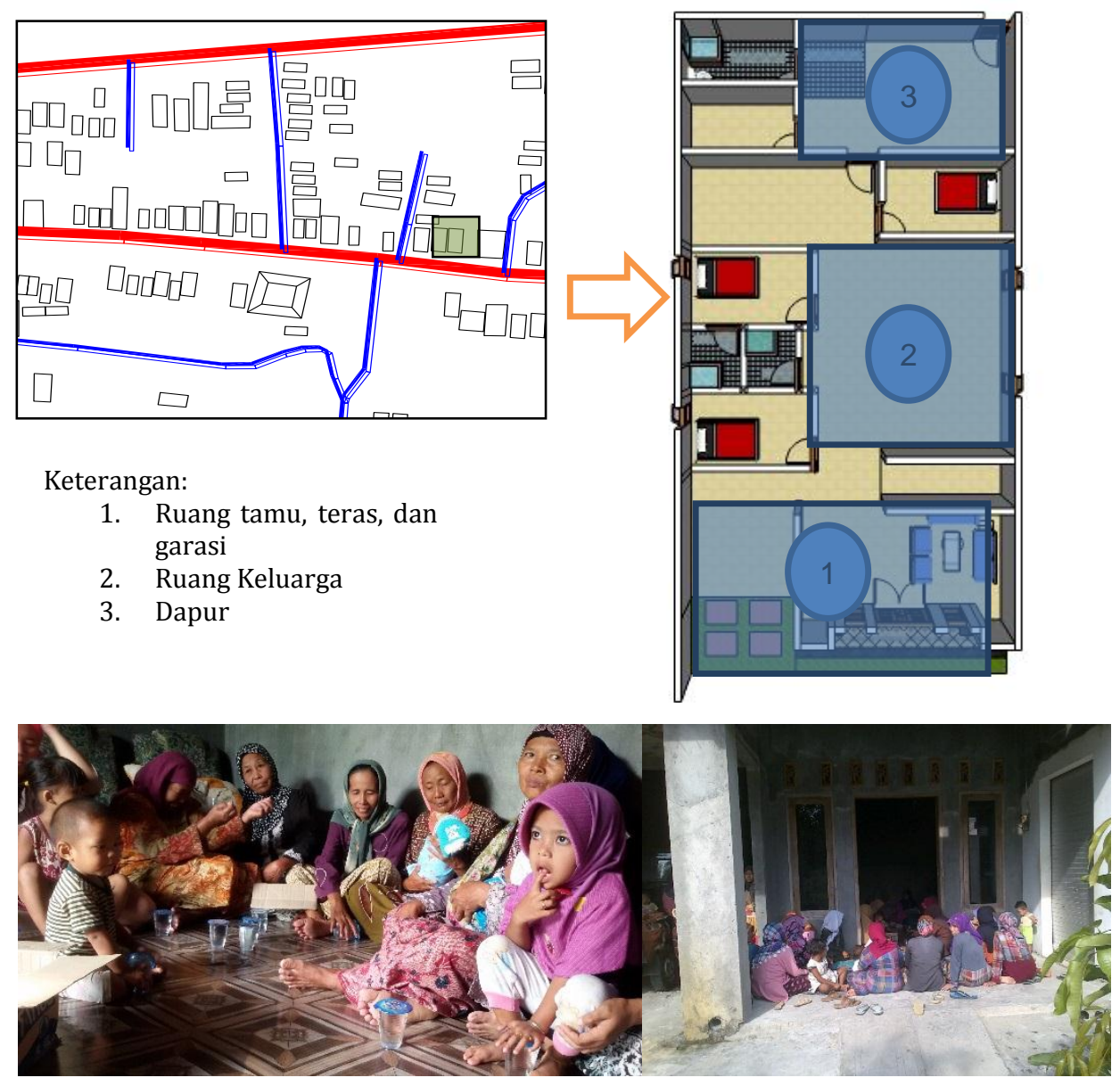

Gambar 5. Pengunaan ruang ritual brokohan

c. Pupak Puser

Kegiatan pupak puser merupakan terlepasnya tali pusar yang menempel di perut bayi, setiap bayi lamanya pupak pusar berbeda-beda, paling cepat 3 hari sampai hingga 14 hari setelah hari kelahiran. Mengenai lamanya waktu, memiliki mitos jika kurang dari satu minggu maka kalau besar nanti anaknya tidak bisa awet kalau memiliki/menggunakan sesuatu.Dalam tradisi, kalau puser belum copot, belum boleh di kasih nama. Nantinya bisa sakit-sakitan 
karena tidak kuat menahan beratnya nama, makanya orang dahulu kalau anaknya sakit-sakitan, namanya sering diganti, katanya "kabotan jeneng".

Kegiatan selamatan pupak puser dilakukan oleh orang tua bayi yang dilaksanakan di rumah, dengan mengundang tetangga sekitar rumah, acara berlangsung setelah maghrib, yang dilakukan saat acara adalah membaca tahlil untuk bayi, setelah acara selamatan berakhir dilakukan melekan hingga jam 12 malam. Ruang yang digunakan untuk kegiatan pupak puser menggunakan ruang tamu, teras dan halaman.

d. Aqiqah

Aqiqah dalam Islam berarti ungkapan rasa syukur atas kelahiran anak yang baru lahir, hewan yang dipotong untuk acara aqiqah adalah hewan kambing atau domba, dimana bila jenis kelamin bayi perempuan, maka kambinng atau domba yang di potong sebanyak satu, dan bila bayi berjenis kelamin perempuan maka kambing yang dipotong berjumlah 2 (dua) ekor.Pelaksanaan aqiqoh di Dusun Wedoro dilaksanakan dengan acara pupak puser.

e. Selamatan bayi usia 3 bulan dan usia 7 bulan (mudun lemah)

Selamatan ini dilaksanakan hampir sama seperti selamatan pada umumnya, dimana tetangga di undang untuk melakukan suatu pegajian, yang khusus terjadi saat bayi berusia 7 bulan diadakan tradisi mudun lemah, dimana bayi akan diminta untuk memilih beberapa barang yang telah disiapkan seperti buku, pensil, uang, perhiasan dan lain-lain, pelaksanaan mudun lemah ini dilaksanakan di ruang tamu.

\section{f. Sunnatan}

Sunnatan atau khitan merupakan hal yang wajib dilakukan untuk umat muslim khusus laki-laki, acara khitan dapat dilakukan saat bayi ataupun dilaksanakan ketika anak sudah cukup besar, biasanya berumur 8 sampai dengan 10 tahun. Biasanya dilaksanakan dengan mengundang tetangga dan melakukan khotmil qur'an, kegiatan khitan sendiri dapat dilakukan di klinik atau dilakukan di rumah mantri desa.

Tabel 1. Perubahan ruang saat aktivitas ritual kelahiran

\begin{tabular}{l|l|l|l|l}
\hline No & \multicolumn{1}{|c|}{ Aktivitas } & \multicolumn{1}{c}{ Ruang } & \multicolumn{1}{c}{ Kondisi Sehari-Hari } & \multicolumn{1}{c}{ Saat Aktivitas Ritual } \\
\hline
\end{tabular}




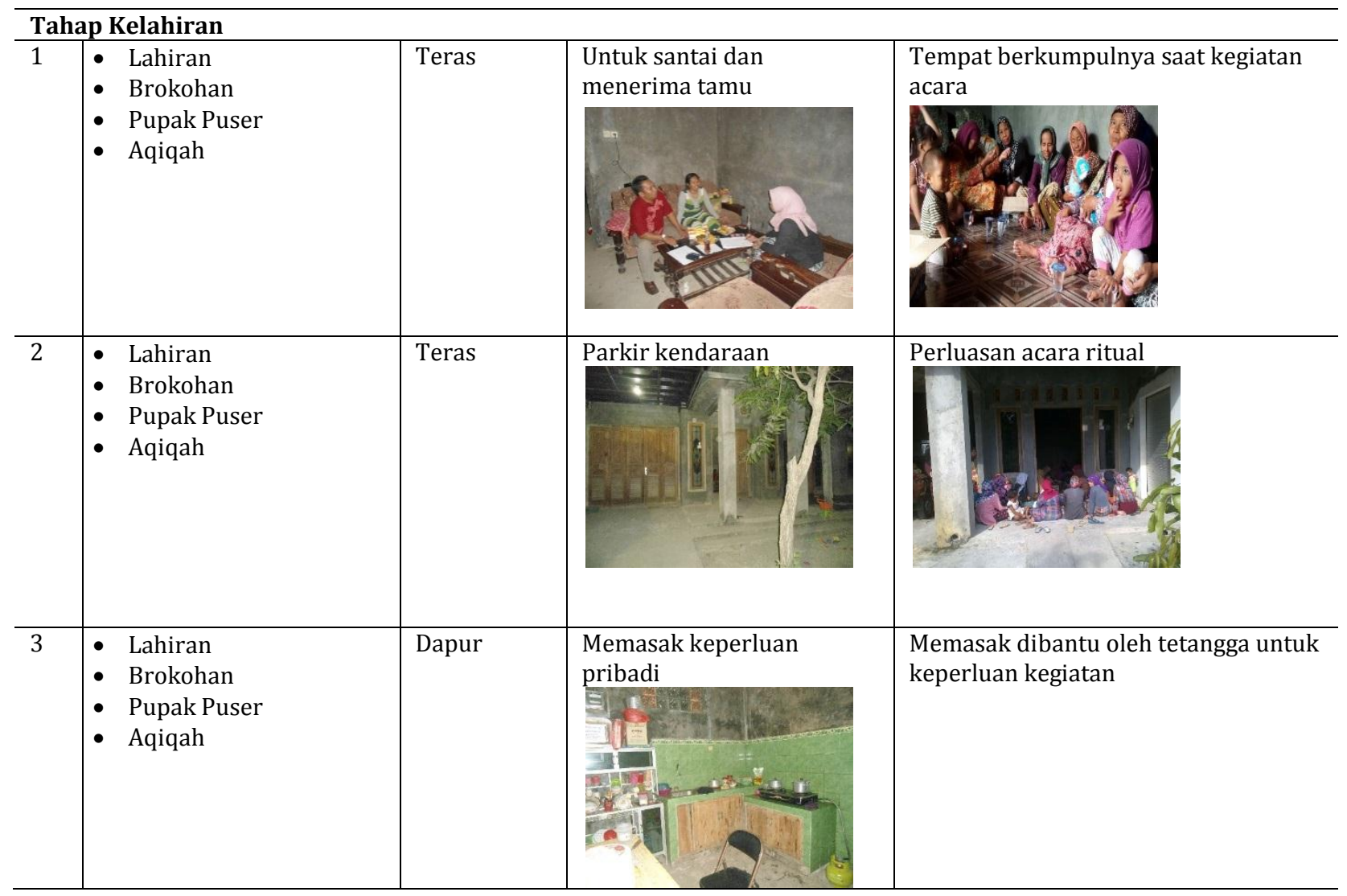

Kegiatan ritual daur hidup,yang lain adalah kelahiran yang dapat membentuk ruang budaya dalam skala mikro, dapat terlihat pada tabel 2 dan gambar 6 .

Tabel 2. Pengunaan ruang kegiatan daur hidup kelahiran

\begin{tabular}{llcccccc}
\hline No & \multicolumn{5}{c}{ Aktivitas } & \multicolumn{5}{c}{ Makro } & \multicolumn{5}{c}{ Meso dan Mikro } \\
& & A & B & C & a & b & c \\
\hline 1 & Selamatan 4 Bulanan & $\sqrt{ }$ & - & - & $\sqrt{ }$ & - & - \\
2 & Selamatan 7 Bulanan & $\sqrt{ }$ & - & - & $\sqrt{ }$ & - & - \\
3 & Lahiran & - & $\sqrt{ }$ & - & - & $\sqrt{ }$ & - \\
4 & Brokohan & $\sqrt{ }$ & - & - & $\sqrt{ }$ & - & - \\
5 & Pupak Puser & $\sqrt{ }$ & - & - & $\sqrt{ }$ & - & - \\
6 & Aqiqoh & $\sqrt{ }$ & - & - & $\sqrt{ }$ & - & $\sqrt{ }$ \\
7 & Sunat & $\sqrt{ }$ & - & $\sqrt{ }$ & $\sqrt{ }$ & - & $\sqrt{ }$ \\
\hline Jumlah & $\mathbf{6}$ & $\mathbf{1}$ & $\mathbf{1}$ & $\mathbf{6}$ & $\mathbf{1}$ & $\mathbf{2}$ \\
\hline
\end{tabular}

\section{Keterangan}

Rumah
A: Rumah Ibu Melahirkan
a : Ruang Tamu
B: Rumah Bidan
b : Kamar
C: Rumah Mantri
c : Halaman 


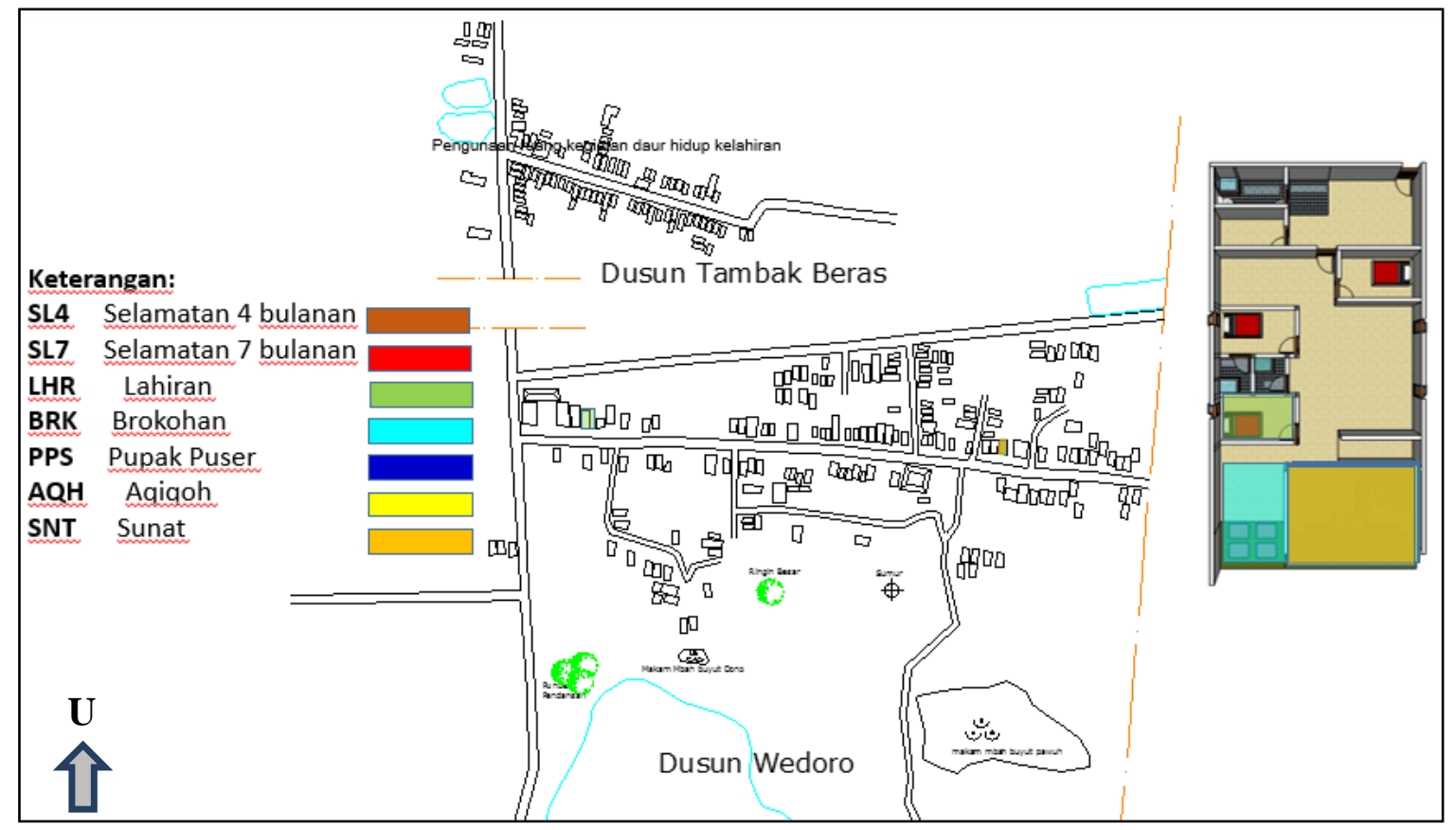

Gambar 6. Pembentukan ruang budaya ritual kelahiran

Dari gambar 6 terlihat ruang yang paling gelap adalah rumah pemilik acara secara makro bila dilihat dari Dusun Wedoro dan ruang tamu dalam skala mikro hunian. Kegiatan di ruang tamu dan halaman merupakan ruang dengan kuantitas paling sering digunakan.

\section{Kesimpulan}

Dari hasil hierarki penggunaan ruang dari ritual kelahiran yang ada di Dusun Wedoro diantaranya:

a. Ruang

Aktivitas ritual menghasilkan ruang budaya, pada ritual kelahiran ruang yang dihasilkan berupa ruang mikro. Kegiatan tersebut tidak hanya dipengaruhi oleh pelaksanaan saja, atribut ruang yang digunakan menunjukkan adanya kegiatan yang tidak biasa.

b. Pelaku

Hasil analisis menyatakan beberapa tokoh kunci yang sering terlibat dalam ritual kelahiran, yaitu dukun bayi.

c. Pelaksanaan

Pelaksanaan kegiatan kelahiran di Dusun Wedoro, sangat dipengaruhi oleh waktu, waktu yang sering digunakan adalah antara setelah maghrib hingga malam hari.

\section{Daftar Pustaka}

Laurens J. M. 2004. Arsitektur dan Perilaku Manusia. Jakarta: PT Grasindo Rapoport, A.1969. House Form and Culture, Englewood Cliffs,N.J. Prentice Hall.Inc

Titisari, Ema Y., Yusran, Yusfan Adeputera. 2000. Metode penulisan Jurnal Arsitektur. Malang: UB Press.

Wibowo H.A., Wasino, \& Setyowati D.L. 2012. Kearifan Lokal dalam Menjaga Lingkungan Hidup (Studi Kasus Masyarakat Di Desa Colo Kecamatan Dawe Kabupaten Kudus). Jurnal of Education Social Studies, Volume 1 Nomor 1 tahun Halaman 25-30 tahun 2012. 